Clinical Toxicology of Commercial Products

Acute Poisoning (Home and Farm). By Marion $\mathrm{N}$. Gleason, Robert E. Gosselin and Harold C. Hodge. Second edition. Pp. $\mathrm{xv}+1211$. (London: Baillière, Tindall and Cox, 1963.) $176 s$.

CLINICAL Toxicology of Commercial Products consists of eight sections, separately paginated and each printed on differently tinted paper, but bound together as a single book. Section 1 (pp. 15) relates to general first-aid and emergency treatment in the event of acute chemical poisoning, both before and when medical aid becomes available. Section 2 (pp. 141) is an index to the active ingredients of some 3,000 proprietary and other substances; toxicity ratings from 1 to 6 (practically non-toxic to 'super-toxic') are ascribed to tho principal chemicals included, while broad classos of compounds are identified with one of 77 specific congeners, these being separately indexed with toxicological details, symptoms and treatment in Section 3 (therapeutic index, pp. 157). General remedial measures, from respiratory aids to nutritive support, are considered in Section 4 (pp. 76), which is followed by a large index (Section 5, pp. 674) of more than 14,000 trade names of products which might be ingested, either accidentally or suicidally. In this the principal toxic constituents are identified by an asterisk, though in practice such might number as many as (say) five of a total of seven listed ingredients. Cleaning fluids, pesticide formulations and sedative tablets all foature prominently; entries, most of which are American proprietaries, range widely, from 'Lifebuoy Soap' to 'Kitty Chaperone' (keeps cats off furniture). Formulations are indexed by function in Section 6 (pp. 113) and by manufacturer in Section 7 (pp. 22). The final section (pp. 13) is a provisional classification of chemicals which either have proved, or may provo to be, poisonous in man, with a numerical ætiological assignation; the latter is an extension of an existing classification and, as such, a contribution to the rationalization of the subject, despite many necessary compromises.

There is no suggestion that this large volume is an emergency ready-reference volume. It could be used as such only after familiarity with the basic plan has been acquired, when (as in other circumstances) the initial logical sequence of consultation might be to Sections 5 (or, failing this, 6), 2 and 3 . Such an approach, with a somewhat extended explanation, is set out diagrammatically as the frontispiece. As a reference source-book there is no doubt of its value, the main limitation to which in Britain lies in the fact that the proprietaries are mainly of North American origin.

H. EGAN

\section{Progress in Chemical Toxicology}

Vol. 1. Edited by Abraham Stolman. Pp. xii +436 . (New York: Academic Press, Inc.; London: Academic Press, Inc. (London), Ltd., 1963.) 14 dollars.

T HIS book, the first of a continuing series of volumes covering developments in chemical toxicology, is divided into eloven somewhat unevenly balanced chapters. For example, the chapter by Rieders on "The Determination of Antiarthritics, Antihistamines and Thymoleptics" occupies 7 pages, whereas "Narcotics and Related Bases" by Farmilo and Genest covers 87 pages. I should havo thought that with a more consistent classification (either pharmacological or analytical classification, but not both) of chapters, the 7-page chapter could have been incorporated in one of the other manuscripts.

Chapter 1, by Freimuth, briefly describes isolation and separation techniques for identification of poisons. Then follows a chapter by Goldbaum, Schloegel and Dominguez on the application of gas chromatography to toxicology. Aliphatic alcohols are thoroughly covered by Harger and Forney, and Curry, in a well-written and informative chapter, discusses the analysis of acidic and neutral poisons. There is a useful chapter by McBay and Algeri on ataraxics and non-barbiturate sedatives. Feldstein deals effectively with the toxicity of, and analytical mothods for, air pollutants. Tyler contributes 43 pages on poisonous mushrooms, and Schwarting concludes the volume with a chapter on poisonous seeds and fruits.

It is a pity that this volume should have taken such a long time before its final publication. I am aware that one of the contributors sent his manuscript to tho editor early in 1962. The editor's preface is dated August 1963. The book appeared in 1964. I feel that neither the editor nor the publishers are to be blamed for the delay, and that this is due to the lack of a sense of urgency and complete co-operation on the part of one or some of the contributors. A book of this type is of greatest value when the date of its appearance is as close as possible to the date of publication of the papers on which the various chapters are based. Some way of dealing effectively with procrastinating contributors should be devised.

Otherwise, part of the volume is a useful compilation of some of the advances which have taken place in chemical toxicology in recent years. H. V. STREeT

Meristems, Growth and Development in Woody Piants An Analytical Review of Anatomical, Physiological and Morphogenic Aspects. By J. A. Romberger. (U.S. Department of Agriculture Technical Bulletin, No. 1293.) Pp. vi +214 . (Washington, D.C.: Government Printing Offico, 1963.) 1.75 dollars.

$\mathbf{N}$ this monograph the author, as his sub-title indicates, 1 has attempted to give an account of aspects of the morphogenesis, anatomy and physiology of selected gymnosperms and woody angiosperms. His approach thus combines in a useful manner the classical methods of anatomists of an earlier period with those of contemporary investigators of plant morphogenesis. It is valuable to have the several accessions of information brought together, briefly but in sufficient detail, in ono volume-the book is primarily intended for students of physiology, horticulture and forestry-though, unavoidably, there are repetitions of facts and concepts that have received wide publicity in recent years. The general objective, maintained throughout, has been to relate growth, development and the functional activities of organs to the physiological processes in main and lateral shoot meristems (and also in other meristems, for oxample, roots) from which they all originate.

In tho section dealing with anatomy and 'physiological morphology', a useful range of information, some familiar, but some less familiar, is clearly and fairly presented and discussed. In other sections, the episodic growth and dormancy of shoots, and the physiological processes that are, or may be, involved, are discussed in some detail, with reference to Pinus sylvestris and selected woody dicotyledons. In this section the phenomena of photomorphogenesis, Circadian rhythms, endogenous growth regulators, etc., are critically examined. A final section provides a useful account of episodic growth and dormancy in roots. The author, whose attitude is one of moderated scepticism, has properly been the critic of his own efforts and of the contemporary state of botanical science as ho soos it. As he notes in his retrospective survey: "The reader who expects a pithy summary, repleto with sweeping truths about the behaviour of meristems, the control of growth and development, and the physiological basis of dormancy, will be disappointed". Quite simply, botanical science has not yot roached that point. But, as the present volume indicates, many avenues of approach to the central problems are now being explored, and progress, though often fragmentary and highly incomplete, is being made.

The book, which is clearly and succinctly written, sometimes in a provocative but agreeable style, is modestly illustrated and well produced. $\quad$ C. W. WARDIAW 